\title{
Иммунный статус, функциональные показатели печени и тяжесть эндогенной интоксикации при разных формах синдрома системной воспалительной реакции у больных при остром калькулезном холецистите
}

\author{
Дж. Н. Гаджиев ${ }^{1}$, Н. Дж. Гаджиев ${ }^{1}$, 3. Б. Мамедова ${ }^{2}$ \\ ${ }^{1}$ Азербайджанский медицинский университет, г. Баку, Республика Азербайджан, \\ ${ }^{2}$ Нахичеванский диагностический лечебный центр, Республика Азербайджан
}

\section{The immune status, hepatic functional indices and severity of endogenous intoxication in different forms of the systemic inflammatory reaction syndrome in patients with an acute calculous cholecystitis}

\author{
J. N. Gadjiyev ${ }^{1}$, N. J. Gadjiyev ${ }^{1}$, Z. B. Mamedova ${ }^{2}$ \\ ${ }^{1}$ Azerbaijan Medical University, Baku, Republic of Azerbaijan, \\ ${ }^{2}$ Nakhichevan Diagnostic Treatment Centre, Republic of Azerbaijan
}

Реферат

Проанализированы результаты изучения статуса цитокинов, интенсивности перекисного окисления липидов (ПОЛ), тяжести эндогенной интоксикации (ЭИ), функционального состояния печени при разных формах синдрома системной воспалительной реакции (ССВР) у 82 больных острым калькулезным холециститом (ОКХ). У 68 больных выявлены признаки ССВР, у 14 - их не было. В сыворотке крови больных в динамике определяли содержание провоспалительных (фактор некроза опухолей- $\alpha$ - ФНО- $\alpha$, интерлейкинов-6 - ИЛ-6) и противовоспалительных (ИЛ-4, ИЛ-10) цитокинов, диеновых конъюгат (ДК), малонового диальдегида (МДА), С-реактивного протеина (СРП), общего белка, альбумина, общего билирубина, активность каталазы (КАТ), аланинаминотрансферазы (АЛТ), аспартатаминотрансферазы (АСТ), щелочной фосфатазы (ЩФ), гаммаглутамилтрансферазы (ГГТ). Установлено, что выраженность дисбаланса цитокинов, интенсификации ПОЛ, тяжести ЭИ, нарушений функционального состояния печени зависела от числа критериев ССВР.

Ключевые слова: острый калькулезный холецистит; сепсис; иммунный статус.

Abstract

Results of studying of the cytokines status, the lipids peroxidal oxidation (LPO) intensity, the endogenous intoxication severity, hepatic functional state in various forms of the systemic inflammatory reaction syndrome (SIRS) were analyzed in 82 patients, suffering an acute calculous cholecystitis. In 68 patients the SIRS signs were revealed, in $14-$ they were absent. The content of antiinflammatory (TNF- $\alpha-\mathrm{FNO}-\alpha$, interleucines-6-(IL-6) and anti-inflammatory (IL-4,IL-10) cytokines, dienic conjugates, malonic dialdehyde, $\mathrm{C}$-reactive protein, general protein, albumin, general bilirubin, activity of catalase, alaninaminotransferase, aspartataminotransferase, alkaline phosphatase, gammaglutamyltransferase were determined in dynamics in the blood serum. There was established, that degree of the cytokines misbalance, the LPO intensification, the endogenous intoxication severity have depended upon the SIRS criteria present.

Keywords: acute calculous cholecystitis; sepsis; immune status.

Желчнокаменную болезнь (ЖКБ) выявляют у 40\% населения в мире [1, 2], более чем у 90\% из них она осложняется ОКХ [3, 4], что обусловливает приоритетность проблемы.

В любой воспалительной реакции, в том числе ССВР, центральную роль играет каскад цитокинов, которые регулируют инициацию и все последующие этапы воспаления [5]. При чрезмерной активации цитокинов как экзогенными, так и эндогенными продуктами происходит их неконтролируемый синтез, увеличивается системный эффект провоспалительных цитокинов, возникает генерализация воспаления, реакция организма на воспаление становится системой, формируется ССВР.
В возникновении и прогрессировании ССВР определенную роль играют процессы липопероксидации и повышение активности фосфолипаз [6, 7].

Процессы ПОЛ и система антиоксидантной защиты (AO3) организма тесно связаны с иммунным статусом, поскольку все иммунные реакции являются кислородзависимыми. Процессы ПОЛ как необходимое метаболическое звено в норме протекают на стабильном уровне и являются одним из важных процессов в регулировании жизнедеятельности клеток. Однако в определенных условиях (травма, воспаление, ишемия, гипоксия и др.) при значительной интенсификации ПОЛ возникает дисбаланс в системе ПОЛ-АОЗ - оксидантный стресс 
с образованием избыточного количества свободных радикалов. В итоге, повреждаются как одиночные молекулы, так и клетки на уровне мембран и тканей органов [8, 9].

На фоне значительных успехов в изучении этиологии, патогенеза, клиники, хирургического лечения ОКХ, некоторые вопросы, в частности особенности профиля цитокинов, состояние процессов липопероксидации, тяжесть ЭИ при ССВР недостаточно изучены.

Целью исследования явилось изучение нарушений статуса цитокинов, состояния ПОЛ, тяжести ЭИ, а также функционального состояния печени при ССВР в зависимости от числа критериев у больных при ОКХ.

\section{Материалы и методы исследования}

Под наблюдением находились 82 больных, у которых выявлены различные формы ОКХ. Больные распределены на 2 группы: у 68 больных (1-я группа) отмечены признаки ССВР, соответствующие критериям, предложенным на согласительной конференции Всемирного общества пульмонологов и общества специалистов критической медицины (АCCP/SCCM в Чикаго, 1992); 14 больных (2-я группа) без признаков ССВР не было (CСBP 0).

В 1-й группе ССВР 2 выявлена у 25 больных, ССВР 3 - у 17, ССВР 4 - у 14; у 12 пациентов состояние оценено как сепсис.

Содержание в периферической крови провоспалительных (ФНО- $\alpha$, ИЛ-6) и противовоспалительных (ИЛ-4, ИЛ-10) цитокинов определяли у больных при госпитализации методом иммуноферментного анализа (ИФА) с использованием набора реактивов ООО «Протеиновый контур» (Санкт-Петербург). Баланс про- и противоспалительных цитокинов оценивали путем определения соотношения ФНО- $\alpha /$ ИЛ-10. В качестве молекулярного биомаркера ССВР и сепсиса определяли содержание СРП. Состояние ПОЛ - АОЗ оценивали по уровню в плазме ДК, МДА и активности КАТ [10].

О функциональном состоянии печени судили на основании анализа уровня общего белка, альбумина, общего билирубина, активности АЛТ, АСТ, ЩФ, ГГТ.

Тяжесть ЭИ оценивали путем определения содержания пептидов средней молекулярной (СМП) массы (ПСММ), а также остаточного азота, мочевины и креатинина в крови.

За норму приняты показатели у 12 практически здоровых лиц.

Статистическая обработка полученных данных проведена с использованием метода вариационной статистики и непараметрического анализа (УилкоксонаМанна-Уитни).

\section{Результаты и их обсуждение}

По данным проведенного исследования, содержание ФНО- $\alpha$, ИЛ-6 и ИЛ-4 в сыворотке крови больных обеих групп статистически достоверно увеличено по сравнению с таковым в норме, наиболее выраженно - у больных 1-й группы. При сравнительной оценке уровня противовоспалительного цитокина ИЛ-10 установлено его повышение у больных 2-й группы и снижение - у больных 1-й группы по сравнению с показателем у здоровых лиц. Установлены достоверные различия изученных показателей между группами. Так, у больных 1-й группы при госпитализации концентрация в периферической крови ФНО- $\alpha$ статистически достоверно превышала таковую в норме и у больных 2-й группы соответственно в 7,7 и 3,3 раза; ИЛ-6 - в 15,3 и 6,7 раза, ИЛ-4 - в 8,4 и 2,1 раза; содержание противовоспалительного цитокина ИЛ-10 было на 43,8 и 57,5\% меньше. Соотношение $Ф$ НО- $\alpha /$ ИЛ-10 превышало его значение в норме $15,3$ раза ( $\mathrm{p}<0,001)$, у больных 2 -й группы - в 8,1 раза $(\mathrm{p} 1<0,001)$.

При сравнительной оценке системного уровня изученных цитокинов отмечено, что он зависел от числа критериев ССВР и наличия сепсиса: чем больше признаков, тем глубже дисбаланс цитокинов.

Повышение уровня провоспалительных цитокинов в обеих группах, с одной стороны, свидетельствовало, что при ОКХ острый воспалительный процесс способствует его повышению, с другой, при формировании ССВР еще больше повышается уровень ФНО- $\alpha$ и ИЛ-6. У больных 1 -й группы на фоне повышенного уровня как провоспалительных цитокинов ФНО- $\alpha$, ИЛ-6, так и противовоспалительного цитокина ИЛ-4, концентрация ИЛ10 была меньше, чем в норме. Уменьшение содержания противовоспалительного цитокина ИЛ-10 у больных 1-й группы может быть связано угнетением противовоспалительной защиты вследствие истощения гуморального звена иммунитета. Гиперпродукция противовоспалительного цитокина ИЛ-4 в обеих группах больных свидетельствовала о снижении резервных возможностей иммунитета на фоне его функционального напряжения.

Концентрация СРП в целом у больных 1-й группы при госпитализации в 9,6 раза (р < 0,001) превышала таковую у здоровых лиц и в 4,7 раза (p1 < 0,001) - у больных 2-й группы. Следует отметить, что степень повышения уровня в крови СРП также зависела от числа критериев ССВР и наличия сепсиса. Так, минимальную концентрацию СРП - $(15,3 \pm 0,7)$ мг/л наблюдали при ССВР 2 , максимальную - $(59,8 \pm 4,7)$ мг/л - при сепсисе.

Повышение уровня провоспалительных цитокинов в сыворотке крови сопровождалось увеличением синтеза СРП острой фазы воспаления, поскольку провоспалительные цитокины ФНО- $\alpha$ и ИЛ-6 являются основными индукторами синтеза СРП.

В целом у больных 1-й группы при госпитализации содержание ДК в плазме крови по сравнению с таковым в норме и у больных 2-й группы было соответственно в $2,3$ раза ( $\mathrm{p}<0,001)$ и 1,7 раза $(\mathrm{p} 1<0,001)$; МДА - в 2,4 раза $(\mathrm{p}<0,001)$ и 1,8 раза (p1<0,001) больше; активность КАТ - на 36,7\% (p < 0,001) и 27,3\% (p < 0,001) меньше. При сравнительном анализе изученных показателей ПОЛАОЗ, содержание их изменялось в зависимости от числа критериев ССВР. Так, при ССВР 2 содержание ДК составило $(0,76 \pm 0,03) \mathrm{D}_{233} /$ мл, ССВР $3-(1,01 \pm 0,05) \mathrm{D}_{233} /$ мл, ССВР 4 - (1,22 $\pm 0,07) \mathrm{D}_{233} /$ мл, сепсисе - $(1,37 \pm 0,7)$ $\mathrm{D}_{233} /$ мл. Аналогичная закономерность отмечена и в от- 


\begin{tabular}{|c|c|c|c|c|c|c|}
\hline \multirow{3}{*}{ Показатель } & \multicolumn{6}{|c|}{ Величина показателя в группах ( $\bar{x} \pm$ m) } \\
\hline & \multirow{2}{*}{ в норме } & \multicolumn{4}{|c|}{ в 1-й группе } & \multirow{2}{*}{$\begin{array}{l}\text { во 2-й } \\
\text { группе }\end{array}$} \\
\hline & & CCBP 2 & CCBP 3 & ССВP 4 & сепсис & \\
\hline Общий белок, г/л & $65,2 \pm 3,6$ & $60,9 \pm 1,7$ & $55,9 \pm 2,4^{*}$ & $54,3 \pm 2,7 * \wedge$ & $52,0 \pm 1,4 * \wedge$ & $62,9 \pm 2,8$ \\
\hline Альбумин, г/л & $41,0 \pm 2,2$ & $37,4 \pm 1,2$ & $35,1 \pm 1,6^{*}$ & $32,1 \pm 1,5 * \wedge$ & $28,3 \pm 1,3^{* \wedge}$ & $39,6 \pm 1,9$ \\
\hline Мочевина, ммоль/мл & $4,5 \pm 0,7$ & $8,6 \pm 0,9 *$ & $12,0 \pm 1,5^{*}$ & $14,8 \pm 2,1^{*}$ & $16,3 \pm 2,2 * \wedge$ & $9,7 \pm 1,4 *$ \\
\hline Остаточный азот, ммоль/л & $15,1 \pm 1,3$ & $23,8 \pm 1,6 * \wedge$ & $31,5 \pm 2,6 * \wedge$ & $35,5 \pm 2,1 * \wedge$ & $36,9 \pm 1,7 * \wedge$ & $17,7 \pm 1,7$ \\
\hline Креатинин, мкмоль/л & $65,2 \pm 6,6$ & $84,9 \pm 3,3^{*}$ & $95,7 \pm 4,8 * \wedge$ & $107,3 \pm 7,7^{* \wedge}$ & $143,8 \pm 10,5^{* \wedge}$ & $73,3 \pm 6,8$ \\
\hline Общий билирубин, мкмоль/л & $11,0 \pm 1,3$ & $14,8 \pm 0,9 *$ & $15,4 \pm 1,4^{*}$ & $20,7 \pm 2,5 * \wedge$ & $29,5 \pm 5,0 * \wedge$ & $13,4 \pm 1,9$ \\
\hline ПСММ, г/л & $0,5 \pm 0,02$ & $0,73 \pm 0,02 * \wedge$ & $0,95 \pm 0,05 * \wedge$ & $1,26 \pm 0,08 * \wedge$ & $1,38 \pm 0,08 * \wedge$ & $0,62 \pm 0,02^{*}$ \\
\hline АлТ, U/I & $18,1 \pm 2,5$ & $57,9 \pm 3,2 * \wedge$ & $84,8 \pm 7,0 * \wedge$ & $174,3 \pm 25,7 * \wedge$ & $196,8 \pm 27,8^{* \wedge}$ & $35,6 \pm 3,2 *$ \\
\hline $\mathrm{ACT}, \mathrm{U} / \mathrm{I}$ & $19,5 \pm 3,1$ & $45,9 \pm 3,0 * \wedge$ & $96,7 \pm 7,7 * \wedge$ & $204,6 \pm 25,8^{* \wedge}$ & $285,7 \pm 31,4 * \wedge$ & $35,6 \pm 3,2^{*}$ \\
\hline АСТ/АЛТ & $1,02 \pm 0,07$ & $0,78 \pm 0,03 * \wedge$ & $1,15 \pm 0,04^{\wedge}$ & $1,19 \pm 0,06^{\wedge}$ & $1,55 \pm 0,11 * \wedge$ & $1,0 \pm 0,03$ \\
\hline ЩФ, U/I & $150,5 \pm 26,6$ & $241,5 \pm 18,1^{*}$ & $274,9 \pm 25,6 * \wedge$ & $540,0 \pm 63,8^{* \wedge}$ & $654,3 \pm 96,3 * \wedge$ & $190,6 \pm 25,8$ \\
\hline$\Gamma Г T, ~ U / I$ & $16,5 \pm 2,4$ & $46,4 \pm 4,4 * \wedge$ & $105,6 \pm 8,8 * \wedge$ & $143,1 \pm 20,4 * \wedge$ & $279,4 \pm 54,2^{* \wedge}$ & $21,7 \pm 3,0$ \\
\hline
\end{tabular}

ношении изменений концентрации МДА в плазме: максимальную концентрацию наблюдали при сепсисе $(14,0 \pm 1,17)$ нмоль/мл, в норме - $(3,8 \pm 0,11)$ нмоль/мл. Активность КАТ уменьшалась параллельно с увеличением числа критериев ССВР: при ССВР 2 была на 24,9\% (р $<0,001)$, ССВР 3 - на 38,7\% (p < 0,001), CCBP 4 - на 44,2\% ( $\mathrm{p}<0,001)$, сепсисе - на 49,5\% ( $<$ 0,001) меньше, чем у здоровых лиц.

Поскольку воспалительные процессы имеют «свободнорадикальную природу» и все иммунные реакции являются кислородзависимыми, снижение активности системы AО3, интенсификация процессов ПОЛ отрицательно влияют на иммунную систему, что подтверждают результаты наших исследований.

При гиперпродукции провоспалительных цитокинов в печени уменьшается синтез альбумина, вследствие увеличения продукции медиаторов воспаления, микробных токсинов, цитокинов, липопероксидных метаболитов, продуктов метаболизма возникает ЭИ, нарушается функция печени.

В целом у больных обеих групп при госпитализации отмечены в разной степени выраженные изменения показателей ЭИ и функционального состояния печени. У больных 1-й группы на фоне достоверного снижения уровня общего белка и альбумина, наблюдали значительное увеличение показателей ЭИ и функционального состояния печени по сравнению с таковым у больных 2-й группы. Степень изменения изученных показателей у больных 1-й группы зависела от числа критериев ССВР.

В таблице представлены данные эндогенной интоксикации и функционального состояния печени у больных 1-й группы в зависимости от числа критериев ССВР и 2-й группы без признаков ССВР (ССВР 0).

\section{Выводы}

1. При ССВР у больных с ОКХ возникает дисбаланс статуса цитокинов, выраженность которого зависит от числа критериев ССВР и наличия сепсиса.

2. Дисбаланс цитокинов сопровождается интенсификацией процессов ПОЛ, прогрессированием ЭИ, нарушением функциональных показателей печени, выраженность которого связана с тяжестью ССВР.

\section{References}

1. Beburishvili EV, Bykov AV, Zyubina EN, Burchuladze NSH. Evolyutsiya podkhodov k khirurgicheskomu lecheniyu oslozhnennogo kholetsistita. Khirurgiya. 2005;(1):43-7. [In Russian].

2. Dibirov MD, Tarasenko SV, Kopeykin AA, Kochukov VP. Lechebnaya taktika pri ostrom kholetsistite, oslozhnennom mekhanicheskoy zheltukhoy, u bol'nykh pozhilogo i starcheskogo vozrasta. KHirurgicheskaya praktika. 2011;(2):19-24. [In Russian].

3. Aliev YuG, Kurbanov FS, Popovich VK, i dr. Maloinvazivnoe khirurgicheskoe lechenie ostrogo i oslozhnennogo kalkuleznogo kholetsistita. Moskovskiy khirurgicheskiy zhurnal. 2014;(2):35-8. [In Russian].

4. Danzanov BS, TSyrendorzhiev DD, Khitrikheev VE, Balkhaeva MI. Khirurgicheskiy stress pri lechenii ostrogo kalkuleznogo kholetsistita $\mathrm{i}$ prognozirovanie techeniya posleoperatsionnogo perioda. Byulleten Vostochno-Sibirskogo nauchnogo tsentra Sibirskogo otdeleniya RAMN. 2010;(2):23-9. [In Russian].

5. Gadzhiev DN, Guseynaliev AG, Tagiev EG, i dr. Otsenka tsitokinovogo profilya u bolnykh s ostrym kalkuleznym xoletsistitom. Vestnik SpbGU. 2012;(3):102-8. [In Russian].

6. Vlasov AP, Bunyatyan ND, Grigoreva TI, i dr. Korrektsiya sindroma sistemnogo vospalitelnogo otveta pri khirurgicheskom endotoksikoze. Farmatsiya. 2012;(5):44-8. [In Russian].

7. Zhidovinov AA. Faktory riska i algoritm prognozirovaniya oslozhneniy posleoperatsionnogo perioda u bolnykh s ostroy khirurgicheskoy patologiey organov bryushnoy polosti [tezisy]. Volgograd; 2007. $38 \mathrm{~s}$. [In Russian].

8. Aliev SR, Silina EV, Stupin VA, i dr. Antioksidantnaya terapiya v lechenii bol'nykh s peritonitami. XI s"ezd khirurgov Rossiyskoy Federatsii. Volgograd. 2011;494-5 s.

9. Gadzhiev DzhN, Tarverdiev MN, Gadzhiev NDzh, Allakhverdiev VA. Ozonoterapiya v kompleksnom lechenii peritonitov. Kharkyvska khirurhychna shkola. 2007;(3):64-6. [In Russian].

10. Goryachkovskiy AM. Klinicheskaya biokhimiya. Odessa: Astroprint; 1998. 608 s. [In Russian]. 